\title{
NPS POLLUTION ASSESSMENT IN CHAO LAKE WATERSHED BASED ON ECM
}

\author{
CAO BAO \\ Chinese Research Academy of Environmental Sciences \\ Beijing, China, 100012 \\ caobao@craes.org.cn \\ *XU DA-WEI \\ Faculty of Management and Economics \\ Dalian University of Technology \\ Liaoning Dalian, China, 116024 \\ xudawei@dlut.edu.cn
}

\section{ZHANG YU-HU}

College of Resources Environment \& Tourism

Capital Normal University

Beijing, China, 100048

\begin{abstract}
Chao Lake is one of the five largest fresh lake in China and important to the socio-economy development of Anhui Province. With the enforcement of agricultural development, agriculture planting and stock breeding sectors boosted quickly and None Point Source(NPS) Pollution has become a considerable source contributing to the total pollutants loads into Chao lake. It is essential to study NPS pollutants loading amounts and their spatial distribution for taking effective countermeasures to control NPS pollution. It is a complex task to estimate the contribution of different NPS sources in a large watershed like Chao lake. When there is no extensive pollutant discharge monitoring data, no adequate soil, land use, atmospheric and hydrodynamic data, Export Coefficient Methods (ECM) could be more practical for evaluating NPS pollution and its spatial distribution in large scale watershed. In this paper, ECM was applied using county level statistical datasets(for the year 1990, 2000 and 2009) in Chao lake watershed to assess NPS pollutants loading and their spatial distribution. The research results showed that: The research showed that: i) Total Nitrogen (TN) and Total Phosphorus(TP) generated in Chao lake watershed were 36979, 65042, 77706 and 8973, 23560, 30383 tons respectively for the year 1990, 2000 and 2009, which kept increasing trend for the past three decades; ii) For the year 2009, Livestock/Poultry Breeding sector contributed $73.8 \%$ of the TN generation, which followed by domestic waste water(15.2\%) and fertilizer using(10.9\%). however, Livestock/Poultry Breeding sector contributed $91.7 \%$ of the TP generation; iii) The top three counties were Feixi, Feidong and Wuwei, whose amounts of TN and TP generation accounted for $57 \%$ and $60 \%$ of the whole Chao lake watershed. Therefore effective countermeasures should be taken to control the generation and discharge amount of TP to improve water quality of Chao Lake.
\end{abstract}

\author{
WANG XIU-BO \\ Chinese Research Academy of Land \& Resources Economics \\ Beijing, China, 101149
}

\section{LUO HONG}

Chinese Research Academy of Environmental Sciences Beijing, China, 100012

WANG XIAO

Chinese Research Academy of Environmental Sciences Beijing, China, 100012

Index Terms-Component, formatting, style, styling, insert. Non Point Source Pollution, Export Coefficient Methods, Chao Lake.

\section{INTRODUCTION}

NPS pollution is caused by rainfall or snowmelt moving over and through the ground. As the runoff moves, it picks up and carries natural and anthropogenic pollutants, finally depositing them into lakes, rivers, wetlands, coastal waters and ground water systems [1]. Studies of NPS modeling have always been a core topic in investigations of NPS [2]. NPS studies in western countries were first conducted in the 1960s, and there have since been many NPS models developed [3]. These models can be divided into two categories, empirical or statistical models and physically based or process-based models[4]. Empirical models use monitoring data in typical experimental plots to build empirical relationships between hydrological parameters, such as the export coefficient method[5], hydrograph separation method [6], etc. Physically based models, which consider the internal mechanism of the pollution process, are capable of calculating long time series and have clearer spatial characteristics distributions. However, due to the enormous number of parameters, requirements for a large body of input data, and limited available information, it is difficult to calibrate and validate these models, which restricts their use for large-scale regions[7]. Estimating the contribution of different NPS sources in a large watershed is a complex task, yet in watershed without extensive pollutant discharge monitoring data, no adequate soil, land use, atmospheric and hydrodynamic data, makes Export Coefficient Methods (ECM) more practical to simulate a large watershed. In this paper, ECM was applied in Chao lake watershed to assess NPS 
pollutants loading and their spatial distribution. Proportions of different sources of NPS were analyzed. And finally, countermeasures for the control and prevention of NPS in Chao lake watershed were proposed according to our study.

\section{METHODOLOGIES}

\subsection{The Study Area}

Chao Lake located at the left bank of the middle and lower reaches of the Yangtze River, facing the Yangtze River to its east and bordering the end of Dabie Mountain Ranges to its west, is located in the middle of Anhui province. The watershed area of Chao Lake is $13,500 \mathrm{~km}^{2}$, and the normal water area of the Lake is approximately $800 \mathrm{~km}^{2}$. There are 11 main tributaries in Chao Lake watershed area including Hangbu River, Nanfei River, Pai River, Zhao River, Shiwuli River, Tangxi River, Baishitian River, Shuangqiao River and Zhegao River, which feed into Chao Lake in a radial pattern and overflow into the Yangtze River through Yuxi River after being regulated in Chao Lake. With rapid development of agriculture, excessive chemical fertilizers was used and huge amounts of livestock and poultries were bred, which made Non-Point Source(NPS) pollution becoming one of considerable contributors influencing the water quality of Chao lake.

\subsection{Export coefficient model (ECM)}

The export coefficient model(ECM), which is based on the idea that the nutrient load exported from a watershed is the sum of the losses from individual sources, such as land-use, livestock, rural life, etc., has been in general use because of its simplicity and relative robustness. Moreover, the time step of this method is large (monthly, seasonal or annual), and it allows the use of spatially and temporally based lumped data rather than real-time data, as well as the use of agricultural census data rather than field level data[7]. In recent years, there has been a growing number of ECM based studies of water quality relative to different NPS land uses in China. Luo et al. [8] selected 15 catchments of the Hujiashan Watershed to examine the effect of land use on NPS pollution and found that land use was a controlling factor that determined the amount of nitrogen export. Other studies have used simulated rainfall and field-scale monitoring methods to determine the export coefficients of different land use types as well $[9,10]$. The formulation of ECM is:

$$
L=\sum_{i=1}^{n} D_{i} \times E_{i} \times Q_{i}
$$

Where L is pollutants loads discharged from NPS; $D_{i}$ is discharge coefficient of source $i$; $E_{i}$ is pollutant export coefficient for source $i, Q_{i}$ is quantity of people, livestock, poultry, aquaculture production or chemical fertilizer utilization in the study area.

In our study, parameters used in the ECM were referenced from the following handbooks: i. Life Source Discharge
Coefficient Handbook; ii. Agricultural Pollution Source Fertilizer Loss Coefficient Handbook; iii. Livestock and Poultry Pollution Source Discharge Coefficients Handbook; iv. Aquaculture Pollution Source Discharge Coefficients Handbook. Detail parameters used in our study were shown in Table 1 to 3 .

TABLE I. Average Pollutants Discharging COEFFICIENT FOR RURAL DOMESTIC WASTEWATER AND AQUACULTURE

\begin{tabular}{|c|c|c|c|}
\hline NPS Sources & unit & TP & TN \\
\hline Rural Domestic Wastewater & kg/people.year & 0.16 & 1.83 \\
\hline Aquaculture Production & $\mathrm{g} / \mathrm{kg}$ product & 0.5 & 4.5 \\
\hline
\end{tabular}

TABLE II. Chemical Fertilizer Losses AND Mode PARAmeters

\begin{tabular}{|c|c|c|c|}
\hline Mode & Monitor Type & \multicolumn{2}{|c|}{ Surface Runoff } \\
\hline \multirow{4}{*}{ Mode 31 } & Partition Area & \multicolumn{2}{|c|}{ Southern Highland } \\
\cline { 2 - 4 } & Terrain & \multicolumn{2}{|c|}{ Highland } \\
\cline { 2 - 4 } & Terrace & \multicolumn{2}{|c|}{ Yes } \\
\cline { 2 - 4 } & Land Use Type & \multicolumn{2}{|c|}{ Paddy Field } \\
\cline { 2 - 4 } & Planting Mode & Paddy Rice and Rapeseed Planting \\
Switch \\
\hline \multirow{3}{*}{$\begin{array}{c}\text { Loss } \\
\text { Coefficients } \\
\text { (kg/mu.) }\end{array}$}
\end{tabular}

TABLE III. Average Excreta And Pollutants Produce COEFFICIENT OF LIVESTOCK AND POULTRY

\begin{tabular}{|c|c|c|c|c|c|}
\hline \multirow{2}{*}{$\begin{array}{l}\text { Livestock/ } \\
\text { poultry }\end{array}$} & \multirow{2}{*}{$\begin{array}{c}\text { Feeding } \\
\text { Period } \\
\text { (day) }\end{array}$} & \multirow{2}{*}{\multicolumn{2}{|c|}{$\begin{array}{c}\text { Excretion } \\
\text { (kg/year) }\end{array}$}} & \multicolumn{2}{|c|}{ Pollutants (kg/ton) } \\
\hline & & & & TP & $\mathbf{T N}$ \\
\hline \multirow{2}{*}{ cattle } & \multirow{2}{*}{365} & Feces & 7300 & 1.18 & 4.37 \\
\hline & & Urine & 3650 & 0.4 & 8 \\
\hline \multirow{2}{*}{ pig } & \multirow{2}{*}{199} & Feces & 398 & 3.41 & 5.88 \\
\hline & & Urine & 656.7 & 0.52 & 3.3 \\
\hline goat/sheep & 90 & Feces & 234 & 1.92 & 9.74 \\
\hline chicken & 210 & Feces & 25.2 & 5.37 & 9.84 \\
\hline duck & 210 & Feces & 27.3 & 6.2 & 11 \\
\hline
\end{tabular}

Based on above assumptions, ECM models were applied to assess NPS pollution generation using county level statistical datasets (for the year 1990, 2000 and 2009) in Chao lake watershed, which including rural domestic wastewater, chemical fertilizer losses, livestock/poultry and aquaculture NPS pollutants generation (Table 4). 
TABLE IV. DIFFERENT NPS SOURCES GENERATED IN COUNTY/CITY LEVEL IN CHAO LAKE WATERSHED

\begin{tabular}{|c|c|c|c|c|c|c|c|}
\hline \multirow{2}{*}{$\begin{array}{l}\text { City } \\
\text { /County }\end{array}$} & \multirow{2}{*}{$\begin{array}{l}\text { NPS } \\
\text { Sources }\end{array}$} & \multicolumn{2}{|c|}{1990} & \multicolumn{2}{|c|}{2000} & \multicolumn{2}{|c|}{2009} \\
\hline & & TN & TP & TN & TP & TN & TP \\
\hline Hefei City & \multirow{9}{*}{$\begin{array}{c}\text { Rural } \\
\text { Domestic } \\
\text { Waste } \\
\text { water }\end{array}$} & 492 & 43 & 467 & 41 & 506 & 44 \\
\hline Feidong & & 1658 & 145 & 1776 & 155 & 1718 & 150 \\
\hline Feixi & & 1519 & 133 & 1528 & 134 & 1408 & 123 \\
\hline Shucheng & & 1528 & 134 & 1653 & 145 & 1581 & 138 \\
\hline Chaohu & & 1185 & 104 & 1136 & 99 & 1212 & 106 \\
\hline Lujiang & & 1917 & 168 & 1902 & 166 & 1940 & 170 \\
\hline Wuwei & & 2210 & 193 & 2318 & 203 & 1797 & 157 \\
\hline Hanshan & & 643 & 56 & 670 & 59 & 677 & 59 \\
\hline He County & & 1004 & 88 & 941 & 82 & 953 & 83 \\
\hline Hefei City & \multirow{10}{*}{$\begin{array}{l}\text { Chemical } \\
\text { Fertilizer }\end{array}$} & 221 & 6 & 162 & 4 & 204 & 5 \\
\hline Feidong & & 1613 & 43 & 1584 & 42 & 1392 & 37 \\
\hline Feixi & & 1255 & 33 & 1209 & 32 & 1051 & 28 \\
\hline Shucheng & & 776 & 21 & 746 & 20 & 725 & 19 \\
\hline Chaohu & & 899 & 24 & 844 & 23 & 833 & 22 \\
\hline Lujiang & & 1366 & 36 & 1272 & 34 & 1269 & 34 \\
\hline Wuwei & & 1567 & 42 & 1523 & 41 & 1498 & 40 \\
\hline Hanshan & & 394 & 11 & 389 & 10 & 606 & 16 \\
\hline He County & & 910 & 24 & 860 & 23 & 859 & 23 \\
\hline Total & & 9002 & 240 & 8587 & 229 & 8437 & 225 \\
\hline Hefei City & \multirow{9}{*}{$\begin{array}{l}\text { Livestock } \\
\text { /Poultry } \\
\text { Breeding } \\
\text { Sector }\end{array}$} & 596 & 284 & 4087 & 2104 & 2483 & 1273 \\
\hline Feidong & & 2459 & 1062 & 6185 & 2652 & $\begin{array}{c}1085 \\
5\end{array}$ & 4858 \\
\hline Feixi & & 2749 & 1341 & 7575 & 3734 & $\begin{array}{c}1822 \\
1\end{array}$ & 9404 \\
\hline Shucheng & & 2630 & 1278 & 3657 & 1747 & 5504 & 2757 \\
\hline Chaohu & & 1146 & 540 & 4679 & 2239 & 3997 & 1896 \\
\hline Lujiang & & 2191 & 1070 & 4621 & 2158 & 3929 & 1780 \\
\hline Wuwei & & 1835 & 862 & 7844 & 3821 & 6292 & 2767 \\
\hline Hanshan & & 712 & 336 & 1578 & 752 & 1576 & 768 \\
\hline He County & & 1481 & 691 & 3705 & 1839 & 4478 & 2345 \\
\hline Hefei City & \multirow{9}{*}{$\begin{array}{l}\text { Aquacult } \\
\text { ure } \\
\text { Breeding } \\
\text { Sector }\end{array}$} & 2 & 16 & 8 & 76 & 5 & 48 \\
\hline Feidong & & 2 & 21 & 17 & 156 & 21 & 187 \\
\hline Feixi & & 3 & 23 & 15 & 135 & 17 & 152 \\
\hline Shucheng & & 2 & 17 & 6 & 53 & 17 & 151 \\
\hline Chaohu & & 2 & 20 & 16 & 141 & 16 & 140 \\
\hline Lujiang & & 3 & 24 & 20 & 176 & 19 & 174 \\
\hline Wuwei & & 5 & 41 & 30 & 271 & 28 & 253 \\
\hline Hanshan & & 2 & 14 & 10 & 89 & 9 & 81 \\
\hline He County & & 4 & 32 & 12 & 104 & 10 & 93 \\
\hline
\end{tabular}

\section{RESULTS}

The research results showed that: The research showed that: i) Total Nitrogen (TN) and Total Phosphorus(TP) generated in Chao lake watershed were 36979, 65042, 77706 and 8973, 23560, 30383 tons respectively for the year 1990, 2000 and 2009, which kept increasing trend for the past three decades; ii) For the year 2009, Livestock/Poultry Breeding sector contributed $73.8 \%$ of the TN generation, which followed by domestic waste water(15.2\%) and fertilizer using(10.9\%). however, Livestock/Poultry Breeding sector contributed 91.7\% of the TP generation (Fig. 1,2); iii) The top three counties were Feixi, Feidong and Wuwei, whose amounts of TN and TP generation accounted for $57 \%$ and $60 \%$ of the whole Chao lake watershed (Fig.3,4). iv) Water quality of Chao Lake could meet class III according to the standard of surface water quality except for phosphor, therefore effective countermeasures should be taken to control the generation and discharge amount of TP to improve water quality of Chao Lake.

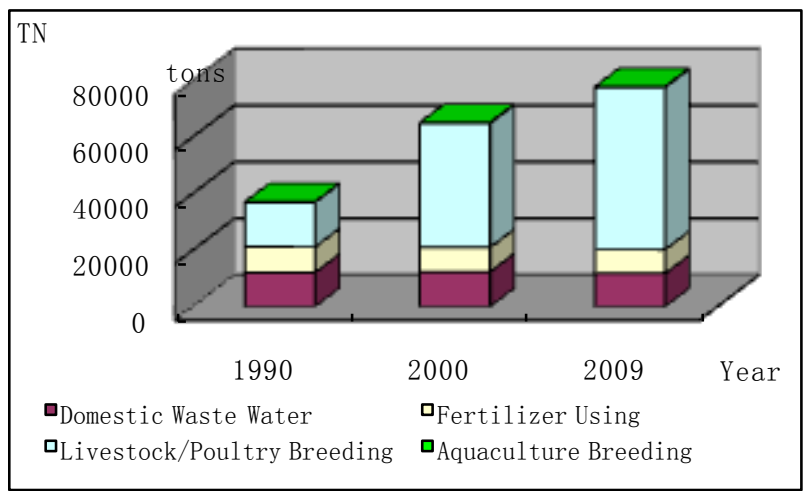

Fig. 1. Contribution of TN Generation in Chao Lake Watershed (1990, 2000, 2009).

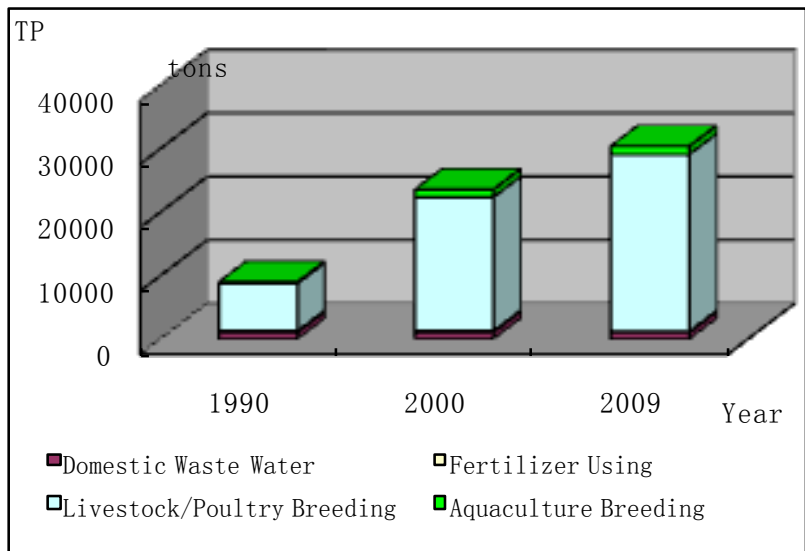

Fig. 2. Contribution of TP Generation in Chao Lake Watershed (1990, 2000, 2009).

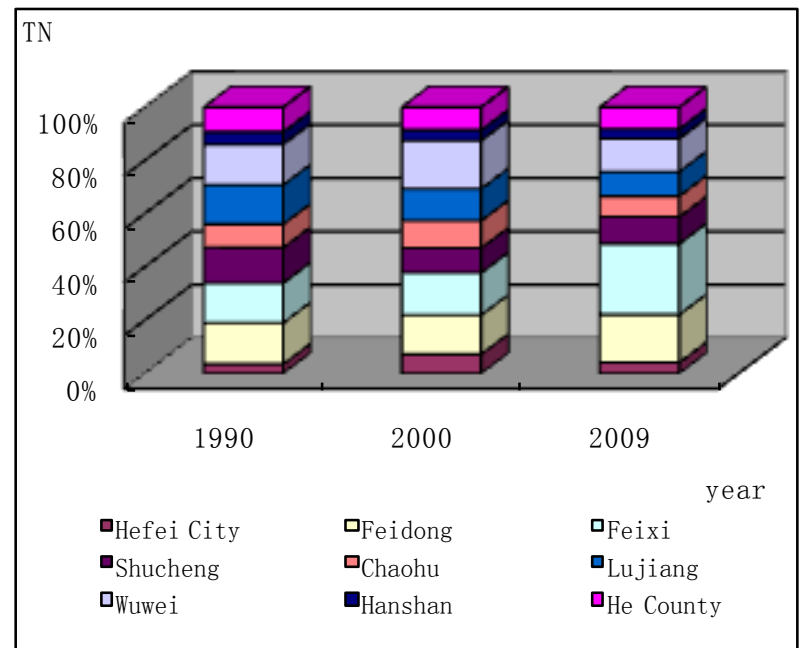

Fig. 3. Proportions of TN Generation in County/City level of Chao Lake Watershed (1990, 2000, 2009). 


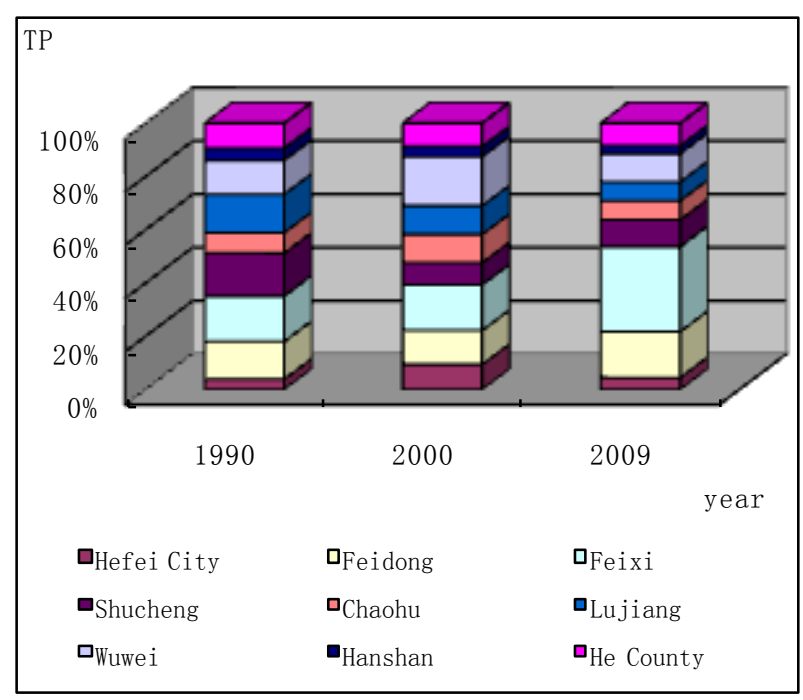

Fig. 4. Proportions of TP Generation in County/City level of Chao Lake Watershed (1990, 2000, 2009).

According to the "Animal Husbandry 12th FYP of Anhui Province", In 2015, the total output of meat, eggs and milk will top 6.3 million tons with an increase of $21 \%$ compared with the year 2010. Collective large scale animal husbandry places will be increased from $55 \%$ in 2010 to $70 \%$ in 2015 . The total amount of livestock, poultry, and aquaculture will rise about $21 \%$ and large scale animal husbandry breeding places will increase $15 \%$ according to this planning. In Chao lake, livestock and poultry breeding plants are still dispersed with livestock and poultry manure disposal is randomly done; thus a considerable part of the excreta pollutants will enter the river system with precipitation runoff and erosion effects. Even if only $1 \%$ of the pollutants generated from livestock/poultry breeding sector follow into rivers/lake, it will contribute considerable phosphor loadings to Chao lake.

The export coefficients parameters of ECM are inherently highly variable and reflect particular site conditions for each study, therefore the choice of an export coefficient from the literature is inevitably subject to considerable uncertainty, especially as agricultural land management practices in China differ greatly from those in the US or UK[10]. Nevertheless, ECM are easy to use and can be scaled up to large watersheds and it was still the wises alternatives for the study of large watershed like Chao lake. Due to the restrict of available data and time, there was not enough calibration work done to validate the accuracy of our study and further research work should be done to support NPS physical based process modeling in future.

\section{ACKNOWLEDGMENT}

The paper is sponsored by Central research institutes of basic research and public service special project of Chinese Research Academy of Environmental Sciences(2012YSKY17); and "National Natural Science Foundation of Chinese Projects" Research on Institution System and Administration Mode of Coastal Ecological \& Environment Damages Compensation in China: Take the oil-spill pollution as example" (71273038); and "Research on Ecological Compensation Mechanism based on Trans-regional Integrated Governing for water environmental improvement of Liao River Basin” (70973013); and 2012 Liaoning finance scientific research project" Research on the performance evaluation of Liaoning east area ecological compensation" (12C004); and National Science and Technology Support Plan During the $12^{\text {th }}$ Five- year Plan Period of China (2012BAC19B03).

\section{REFERENCES}

[1] U.S. EPA, National Management Measures for the Control of Non-point Pollution from Agriculture[R]. EPA-841-B-03-004, US Environmental Protection Agency, Office of Water, Washington, DC, 2003.

[2] W. C. Ma, L. M. Chen, J. Z. Li, Progress in the research of non-point source pollution models of aquatic environment[J]. Advance in Earth Sciences 18, pp. 358-366, 2003. (in Chinese).

[3] W. L. Zhang, et al. A review on non-point source pollution models, Chinese Journal of Applied Ecology , 18, pp. 18861890, 2007. (in Chinese).

[4] F. H. Hao, et al. The significance, difficulty and key technologies of large scale model applied in estimation of nonpoint source pollution[J]. Acta Scientiae Circumstantiae, 26, pp. 362-365, 2006. (in Chinese).

[5] P. J. Johnes. Evaluation and management of the impact of land use change on the nitrogen and phosphorus load delivered to surface waters: the export coefficient modeling approach[J]. Journal of Hydrology, 183, pp. 323-349, 1996.

[6] M. Cai, W. H. Niu, W. Y. Li. Hydrograph separation research of pollution loading watershed[J]. Yellow River, 28, pp. 24-26, 2006. (in Chinese).

[7] Z. Y. Shen, L. Qian, H. Qian, et al. An overview of research on agricultural non-point source pollution modeling in China[J]. Separation and Purification Technology, 84, pp. 104-111, 2012.

[8] X. Luo, etal. Effects of land use structure on nitrogen export in Hujiashan watershed of Danjiangkou reservoir area[J]. Environmental Science, 31, pp. 58-62, 2010.(in Chinese).

[9] T. Liang, et al. Simulation study of non-point source pollution under different land use in Guanting reservoir watershed[J]. Acta Scientiae Circumstantiae, 25, pp. 483-490, 2005. (in Chinese).

[10] Q. Z. Li, D. Y. Wang, B. Zhu. The rule of phosphorus load with runoff in purple soil by not-point source way[J]. Journal of Agro-Environment Science, 23, pp. 1050-1052, 2004.

*Corresponding Author: Xu Dawei, Ph.D, Associate Professor, School of Economics, Dalian University of Technology; Address: Technology Park Building C Building 410 Room, No.2 Linggong Road, Liaoning Dalian, China, 116024; Office Telephone:+86-0411-84707990. 